\title{
Терагерцовое излучение из наноструктур карбида кремния
}

\author{
(C) Н.Т. Баграев ${ }^{1,2}$, С.А. Кукушкин ${ }^{1}$, А.В. Осипов ${ }^{1}$, Л.Е. Клячкин ${ }^{2}$, А.М. Маляренко ${ }^{2}$, В.С. Хромов ${ }^{1,2}$ \\ ${ }^{1}$ Институт проблем машиноведения Российской академии наук, \\ 199178 Санкт-Петербург, Россия \\ ${ }^{2}$ Физико-технический институт им. А.Ф. Иоффе Российской академии наук, \\ 194021 Санкт-Петербург, Россия \\ E-mail: bagraev@mail.ioffe.ru
}

Поступила в Редакцию 12 июля 2021 г.

В окончательной редакции 20 июля 2021 г.

Принята к публикации 20 июля 2021 г.

Впервые обнаружена электролюминесценция в среднем и дальнем ИК-диапазоне из наноструктур карбида кремния на кремнии, полученных в рамках холловской геометрии. Карбид кремния на кремнии был выращен методом согласованного замещения атомов на кремнии. Электролюминесценция из краевых каналов наноструктур индуцируется с помощью продольного тока исток-сток. Спектры электролюминесценции, полученные в терагерцовом частотном диапазоне, 3.4 и 0.12 ТГц, возникают вследствие квантового эффекта Фарадея. В рамках предлагаемой модели продольный ток индуцирует изменение числа квантов магнитного потока в краевых каналах, что приводит к возникновению генерационного тока в краевом канале и, соответственно, к терагерцовому излучению.

Ключевые слова: карбид кремния на кремнии, терагерцовое излучение, электролюминесценция, наноструктура, квантовый эффект Фарадея.

DOI: 10.21883/FTP.2021.11.51556.9709

\section{1. Введение}

В последние годы пристальное внимание уделяется исследованиям, направленным на получение и использование терагерцового излучения (ТГц-излучения) - области спектра электромагнитных волн с частотами в диапазоне $0.1-10$ ТГц $\left(1\right.$ ТГц $=10^{12} Г ц$, этой частоте соответствует длина волны 300 мкм и энергия 4.14 мэВ) [1].

Такое излучение обладает рядом уникальных характеристик. Во-первых, в отличие от рентгеновских лучей энергия ТГц-излучения недостаточна для ионизации молекул. Тем самым исключается риск облучения/повреждения материала [1]. На практике это можно использовать для неразрушающего контроля состояния относительно тонких структур, таких как полимерные, композитные, лакокрасочные и защитные материалы, оболочки фармакологических веществ [2]. Отмечается возможность исследования с помощью ТГц-излучения фононного спектра неорганических и органических молекулярных кристаллов, а также сетки водородных связей в молекулярных твердых телах. Непрозрачность проводящих материалов для ТГц-излучения позволяет в ТГц-спектре различить проводящие и непроводящие фазы с высокой контрастностью [1].

Во-вторых, энергия ТГц-излучения совпадает с энергиями колебательных и вращательных переходов в молекулах и макромолекулах, что делает ТГц-излучение мощным инструментом для их идентификации и исследования их структуры. Подобный терагерцовый спектрометрдетектор может быть приспособлен для исследования последовательностей цепочек ДНК $[1,3]$, выявления специфических для раковых опухолей протеинов, регистрации изменений в структуре молекул в пораженной опу- холью ткани для выявления и исследования динамики поведения последней.

В-третьих, полярные молекулы (вода и жидкости организма) интенсивно поглощают ТГц-излучение. Так, становится возможным использовать ТГц-излучение для биологии и медицины для диагностики с высоким разрешением, основанной на регистрации изменений концентрации воды в тканях или же самого состава жидкости. Вместе со способностью проникать через непрозрачные для видимого и ближнего инфракрасного излучения среды отмечается возможность использовать ТГц-излучение для отслеживания уровня гидратации кожи в реальном времени [1], а также для ранней диагностики рака кожи [1].

Изначально источниками микроволнового излучения высокой частоты (т.е. излучения, близкого по частоте к нижней границе ТГц-излучения) были приборы вакуумной электроники $[4,5]$ : клистроны, лампы бегущей волны, гиротроны, лампы обратной волны [6]. Последние способны покрывать диапазон частот до 1.2 ТГц. Для получения когерентного ТГц-излучения сегодня используются несколько техник: оптическая накачка активной среды (газа) внешним лазерным излучением, понижение частоты с использованием двух лазеров с такой разницей в рабочих частотах, которая составляет требуемую величину в несколько ТГц [5]. Подобные методы требуют габаритного и дорогостоящего оборудования; в частности, в работе [7] используется коммерческая система источника-приемника ТГц-излучения фирмы MenloSystems с фемтосекундным лазером. Общий вес подобной установки (оптомеханическая часть и управляющий модуль) может достигать 54 кг [8]. В лазерной технике излучение ТГц-диапазона было 
продемонстрировано с помощью квантового каскадного лазера в 2002 году [9], что стало следующим шагом после демонстрации излучения в среднем ИК-диапазоне на каскадном лазере в 1994 году [10]. Тем не менее все вышеперечисленное довольно габаритно, и актуальной является проблема создания компактных источников и приемников ТГц-излучения. Одной из первых попыток было получение ТГц-излучения в структуре, содержащей джозефсоновские ВТСП-контакты [11]. Это подтвердило возможность создания систем компактных источников и приемников ТГц-излучения на основе твердотельных образцов, в которых проявляются макроскопические эффекты квантовой интерференции. Следующим шагом было создание подобных компактных источников, работающих при комнатной температуре. Такие источники были созданы на основе кремниевых наносандвичей и используются в практической медицине как при диагностике, так и при лечении социально значимых заболеваний [12]. Излучение в этих наносандвичах генерируется краевыми каналами, ограниченными дипольными центрами бора, которые формируют сетки джозефсоновских переходов [13]. Полученные результаты показали, что для повышения мощности ТГц-излучения в качестве основы наносандвича целесообразно использовать широкозонные материалы [14], среди полупроводниковых соединений таким является карбид кремния.

\section{2. Методика эксперимента}

В качестве элементов такой системы могут быть использованы полупроводниковые образцы, содержащие тонкие пленки монокристаллического $\mathrm{SiC}$, выращенные на поверхностях (100), (110) и (111) монокристаллического Si. Метод получения таких пленок методом согласованного замещения атомов за счет химической реакции кремния с газом монооксида углерода СО был разработан в работах [15-17]. Подробное описание процессов, протекающих при росте $\mathrm{SiC}$ методом замещения атомов, и технологию его синтеза можно найти в обзорах $[18,19]$.

Принципиальным отличием данного механизма роста пленок $\mathrm{SiC}$ от их роста другими методами является сохранение строения исходной кубической решетки $\mathrm{Si}$, что обеспечивает рост именно кубического политипа $3 C$-SiC [18-20]. Это было подтверждено электронномикроскопическими исследованиями, которые также показали, что дислокации несоответствия решеток на границе раздела $3 C-\mathrm{SiC}(111) / \mathrm{Si}(111)$ отсутствуют; вместо них на межфазной границе образуются дефекты упаковки с прослойками гексагональных фаз [21]. Термин „согласованный“ означает, что процессы удаления атома $\mathrm{Si}$ из решетки и встраивания атома $\mathrm{C}$ на его место за счет реакции

$$
2 \mathrm{Si}(\text { crystal })+\mathrm{CO}(\text { gas })=\mathrm{SiC}(\text { crystal })+\mathrm{SiO}(\text { gas }) \uparrow
$$

происходят одновременно [20]. Эпитаксия пленок $\mathrm{SiC}$ на $\mathrm{Si}$ за счет согласованного замещения половины атомов
$\mathrm{Si}$ на атомы C при отсутствии дислокаций несоответствия решеток обеспечивает высокое кристаллическое совершенство пленок $\mathrm{SiC}$ [18-21].

Реакция (1) синтеза карбида кремния протекает в два этапа. На первом образуются комплексы кремниевая вакансия-межузельный атом углерода. На втором этапе углеродные атомы смещаются по направлению к кремниевым вакансиям, образуя карбид кремния. Активированные комплексы превращаются в карбид кремния, а освободившиеся вакансии сливаются в поры под слоем карбида кремния. В результате образуется пленка карбида кремния, частично висящая над порами в кремнии. Вследствие этого в пленках, полученных данным методом, отсутствуют упругие напряжения [15-21]. Ориентация пленки при этом задается „старой“ кристаллической структурой исходной матрицы $\mathrm{Si}$, а не только поверхностью подложки, как это обычно реализуется в традиционных методиках выращивания пленок.

Важной особенностью данного метода роста $\mathrm{SiC}$ является возникновение на границе раздела $\mathrm{SiC} / \mathrm{Si}$ интерфейсного слоя толщиной порядка нескольких нанометров с нестандартными оптическими и электрофизическими свойствами, которые вызваны процессом усадки исходной решетки. На завершающей стадии превращения кремния в карбид кремния исходная решетка материала $\mathrm{Si}$ с параметром решетки $0.543 \mathrm{HM}$ „схлопывается“ в кубическую решетку $\mathrm{SiC}$ с параметром 0.435 нм; этот процесс усадки происходит в плоскости подложки [18,21].

При этом от кремниевой матрицы отделяется новая фаза - карбид кремния, со стороны которого кремний подвергается аномально сильному сжатию, превышающему 100 ГПа. При таких высоких значениях давления невозможно было бы получить $\mathrm{SiC}$ со столь хорошей структурой без совпадения каждой пятой кристаллической ячейки карбида кремния с каждой четвертой ячейкой кремния с высокой точностью. Результатом подобной усадки является согласованное расположение химических связей: каждой пятой связи $\mathrm{SiC} \mathrm{c}$ каждой четвертой связью $\mathrm{Si}$. Остальные связи либо рвутся (откуда и возникают вакансии и поры), либо подвергаются сжатию, которое приводит к изменению структуры поверхностных зон $\mathrm{SiC}$, прилегающего к $\mathrm{Si}$, и его превращению в „полуметалл“. Впервые это явление было недавно экспериментально обнаружено методом спектральной эллипсометрии в диапазоне энергий фотонов $0.5-9.3$ эВ [22].

Квантово-химические расчеты, выполненные в работе [22], показали, что в процессе бездислокационного согласования решеток $\mathrm{SiC}$ и $\mathrm{Si}$, отличающихся на $20 \%$, пленка $\mathrm{SiC}$, обращенная к подложке $\mathrm{Si}$-поверхностью, притягивает один из 16 атомов $\mathrm{Si}$ в ближайшем двойном слое атомов подложки. При этом 22 из 25 атомов $\mathrm{Si}$ образуют химические связи с атомами $\mathrm{Si}$ подложки, a 3 атома из 25 (т.е. 12\%) связей не образуют, так как находятся слишком далеко от атомов подложки (более $3 \AA$ ); -электроны именно этих атомов $\mathrm{Si}$ в $\mathrm{SiC}$ дают 


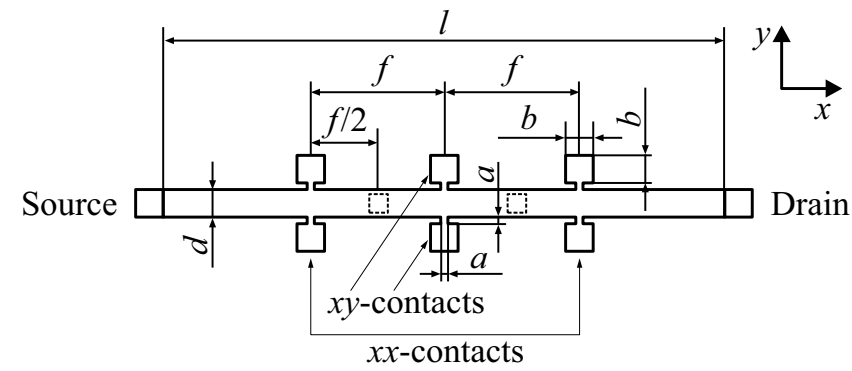

Рис. 1. Холловская геометрия контактов на поверхности исследуемой структуры. Параметры в мкм: $a=50, b=200$, $d=200, l=4200, f=1000$. Пунктиром показаны месторасположения вертикальных контактов размера $b \times b$, сформированных над поверхностью структуры.

основной вклад в узкий и резкий пик плотности электронных состояний $3 C-\mathrm{SiC}(111) / \mathrm{Si}(111)$, находящейся в окрестности энергии Ферми. Иными словами, граница раздела $3 C-\mathrm{SiC}(111) / \mathrm{Si}(111)$ должна обладать необычными электрофизическими свойствами, в частности она должна хорошо проводить электрический ток.

Эта граница также обладает и рядом необычных магнитных свойств. В работе [23] исследовался содержащий пленку карбида кремния на кремнии (110) образец, который был после формирования пленки легирован бором в условиях неравновесной диффузии из газовой фазы в избыточном потоке кремниевых вакансий с поверхности полученных образцов карбида кремния на кремнии. Технологические параметры образца (Ф5) указаны в [23]. Был обнаружен „диа-пара гистерезис“ магнитной восприимчивости, который известен как экспериментальная демонстрация эффекта Мейснера-Оксенфельда, а также осцилляции магнитной восприимчивости с периодом, 2, 13 и 300 Э, идентифицирующие реализацию условий квантовой интерференции в плоскости образца в окрестностях микродефектов. Исследование этих осцилляций проявляет эффекты де Гааза-ван Альфена (дГвА) и Ааронова-Бома (АБ), связанные с квантованием момента и квантованием магнитного потока при комнатной температуре соответственно. Тем самым демонстрируется эффективное подавление электрон-электронного взаимодействия. Это является следствием формирования дипольных центров бора с отрицательной корреляционной энергией, которые ограничивают краевые каналы рассматриваемой структуры и, соответственно, определяют характеристики осцилляций дГвА и АБ [24]. Следует отметить, что кроме дипольных центров бора формировать краевые каналы могут дипольные центры типа кремниевая вакансия-межузельный атом углерода, всегда присутствующие в структурах $\mathrm{SiC} / \mathrm{Si}$, выращенных методом согласованного замещения атомов на поверхностях кремниевой подложки (111) и (110) [20]. Соответственно, наблюдение квантовой интерференции в краевых каналах взаимосвязано с отмеченным выше „диа-пара гистерезисом“ магнитной восприимчивости. Таким образом определяется важная роль областей кван- товой интерференции в формировании джозефсоновских сеток внутри краевых каналов наносандвичей.

Для проведения экспериментов в условиях пропускания тока через образец на его поверхности были сформированы контакты в холловской геометрии, показанные на рис. 1.

\section{3. Результаты и обсуждение}

При помощи фурье-спектрометра Bruker Vertex 70 был исследован спектр электролюминесценции представленного образца. При пропускании через контакты drain-source продольного тока $I_{d s}$ (исток-сток) в миллиамперном диапазоне наблюдался терагерцовый спектр излучения в среднем (рис. 2,a) и дальнем (рис. 2, $b$ и c) ИК-диапазонах. Провалы в спектрах связаны с поглощением излучения водяным паром и углекислым газом, позиции линий поглощения для которых были идентифицированы с помощью базы HITRAN [25]. Так, особенности в области 15 мкм (20 ТГц) связаны с линиями поглощения $\mathrm{CO}_{2}$, а особенности в области 5-8 мкм (60.0-37.5 ТГц) - с набором линий поглощения водяного пара.

Ниже предлагается объяснение полученных результатов в рамках модели генерации ТГц-излучения из краевых каналов исследуемой структуры.

Из магнетополевых зависимостей продольного напряжения $U_{x x}$ исследуемого образца (рис. 3) следует экспериментальное значение периода осцилляций типа АБ: $\Delta B=20$ мТ, откуда можно оценить продольный размер $l_{0}$ области краевого канала, в которой происходит интерференция одиночного носителя:

$$
l_{0}=\frac{\Phi_{0}}{\Delta B d_{0}}
$$

где $\Phi_{0}=h / e-$ квант магнитного потока, а в качестве ширины $d_{0}$ краевого канала можно рассматривать значение 1.54 нм, указанное в работе [18] как характерное расстояние между усадочными порами, образующимися на поверхности кремниевой подложки и покрытыми слоем $\mathrm{SiC}$. Тогда получается значение $l_{0} \approx 0.1344 \cdot 10^{-3} \mathrm{M} \approx 134$ мкм. Можно заключить, что краевой канал исследуемой структуры состоит из областей интерференции одиночных носителей. Каждая область („пиксела“) состоит из содержащих диполи бора слоев размера $S_{\text {pixel }}=134$ мкм $\times 1.54 \mathrm{Hм}$, по которым туннелирует носитель; двумя этими слоями ограничивается сердцевина из $\mathrm{SiC}$ высотой 2 нм, поскольку в процессе легирования образца бором профиль концентрации последнего меняется на расстояниях порядка 2 нм по данным измерений осцилляций дГвА [24]. Схема пикселы показана на рис. 4.

Следует отметить, что при этом на площади $S_{x x}$ краевого канала между $x x$-контактами $S_{x x}=$ $=2000 \mathrm{м \kappa м} \times 1.54 \mathrm{HM}=3.08 \cdot 10^{-12} \mathrm{M}^{2}$ имеется $\frac{2000}{134} \approx 15$ 

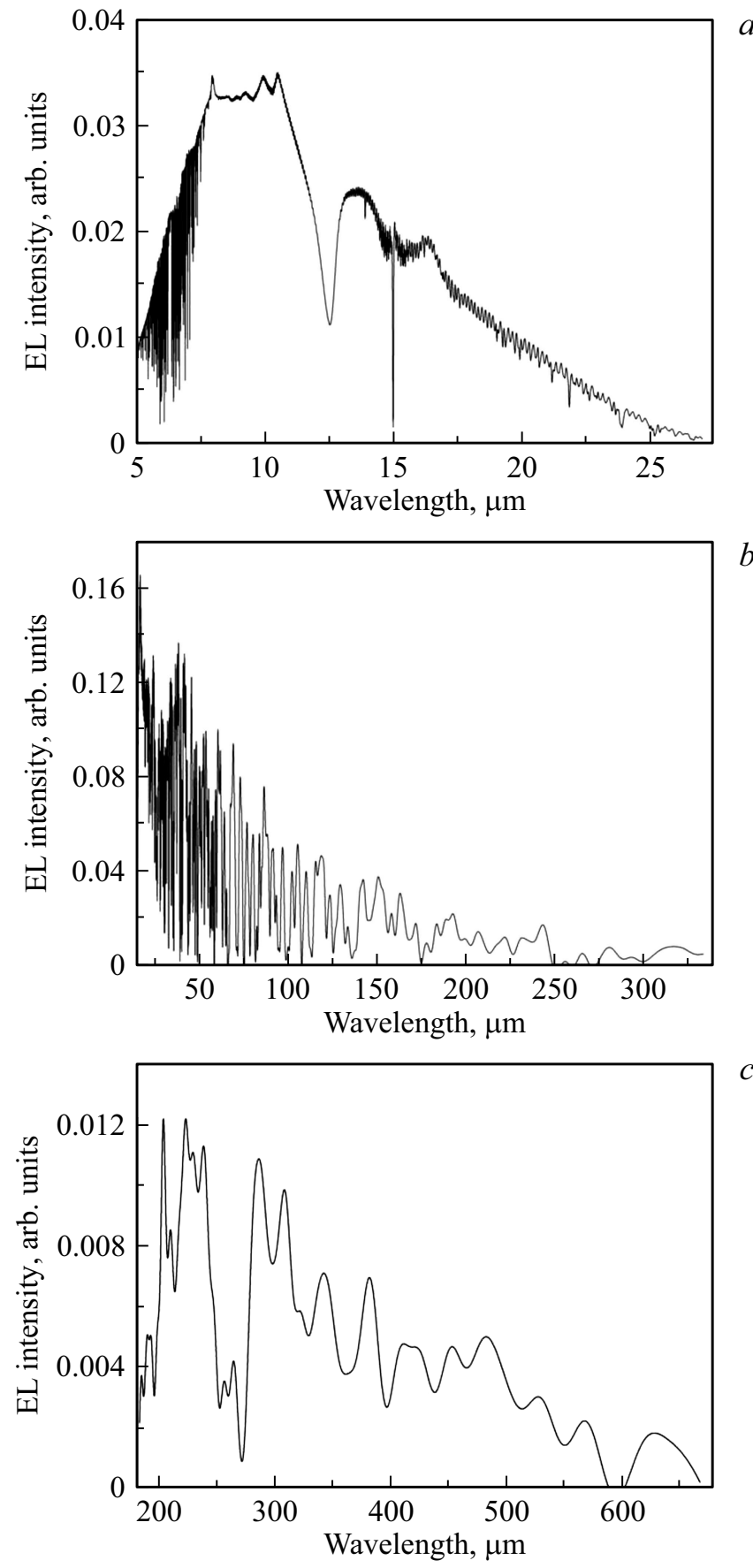

Рис. 2. Спектры электролюминесценции исследуемого образца в среднем (5 - 27 мкм $(a))$ и дальнем ИК-диапазонах $(14-333$ мкм $(b), 182-667$ мкм $(c)) ; I_{d s}=30 \mathrm{мA}$, $T=300 \mathrm{~K}$.

одиночных носителей, что соответствует значению двумерной плотности $n_{2 D} \approx 5 \cdot 10^{12} \mathrm{M}^{-2}$. Данное значение согласуется с величиной, полученной из измерений полевых зависимостей магнитной восприимчивости [23]. Площадь $S_{x x}$ вносит вклад в обнаруженные осцилляции магнитной восприимчивости с периодом $\Delta B_{13 \ni}=13 \ni[23]$ : при изменении магнитного поля на эту величину магнитный поток через пло- щадь $S_{x x}$ увеличивается на величину кванта потока $\Delta B_{13 \ni} \cdot S_{x x}=\Phi_{0}=h / e$.

Подобные области-пикселы проявляют свойство квантованной проводимости [26]. Поэтому краевой канал может рассматриваться как баллистический, в котором каждая из пиксел может характеризоваться сопротивлением, равным кванту сопротивления $h /\left(e^{2}\right)$. Кроме того, если принять во внимание возможность сильного подавления электрон-электронного взаимодействия вследствие отмеченного выше высокого давления порядка сотен ГПа на границе кремниевая подложкакарбид кремния, возможно формирование пиксел удвоенной длины, содержащих пару носителей с вероятной реализацией джозефсоновского перехода вблизи границы микродефекта. В этих условиях формируются пикселы удвоенной длины с геометрическими размерами 268 мкм $\times 1.54$ нм $\times 2$ нм (рис. 5), которые характеризуются сопротивлением, равным $h /\left(4 e^{2}\right)$.

Можно сделать оценки процесса генерации излучения. Пропускаемый через структуру продольный ток $I_{d s}$

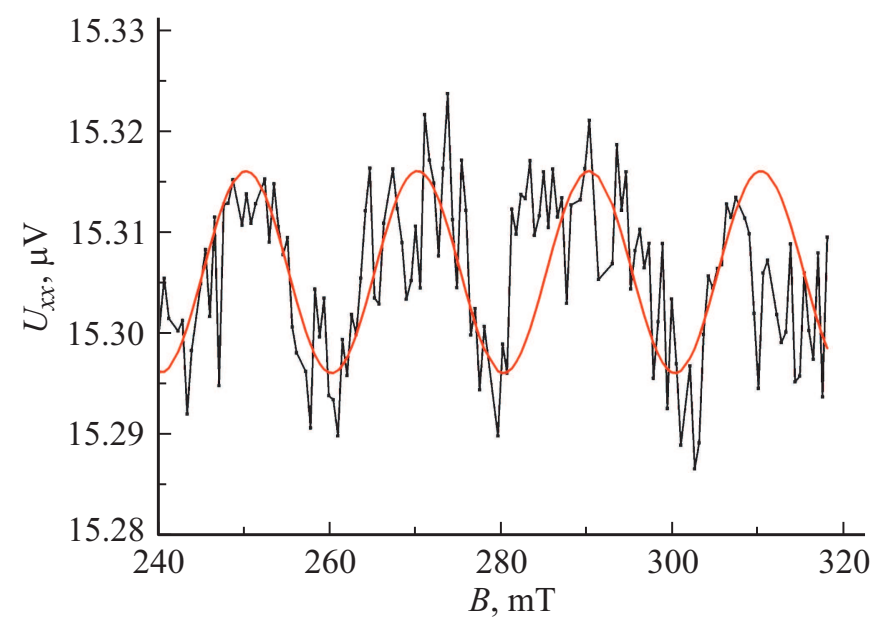

Рис. 3. Зависимость продольного напряжения $U_{x x}$ наносандвича на основе $\mathrm{SiC}$ от величины магнитного поля, приложенного перпендикулярно плоскости образца; красным показана расчетная зависимость осцилляций; $I_{d s}=10 \mathrm{HA}, T=300 \mathrm{~K}$. (Цветной вариант рисунка представлен в электронной версии статьи).

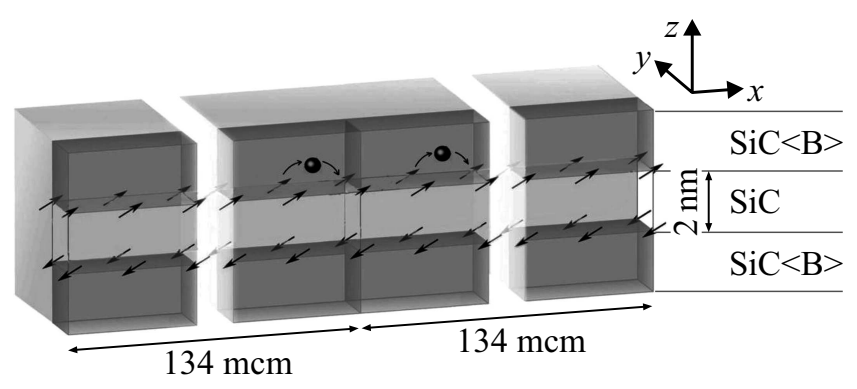

Рис. 4. Схема областей интерференции (пиксел) одиночных носителей с размерами 134 мкм $\times 1.54$ нм $\times 2$ нм. Показано туннелирование одиночных носителей по оболочке из диполей бора, оборачивающей пикселу. 


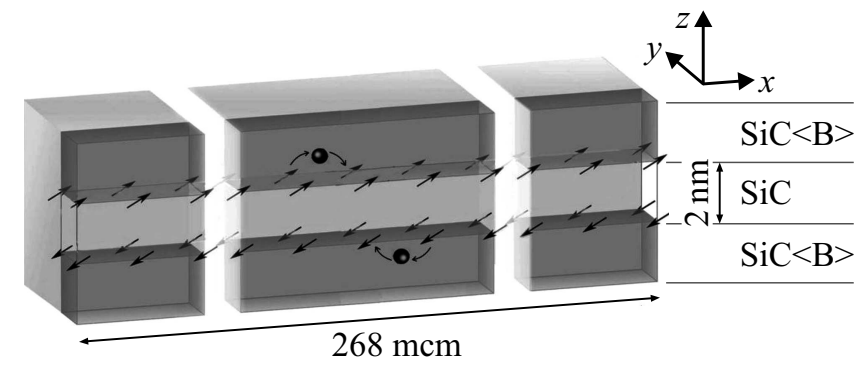

Рис. 5. Схема содержащей пару носителей пикселы удвоенной длины с размерами 268 мкм $\times 1.54 \mathrm{Hм} \times 2$ нм. Показано туннелирование парного носителя по оболочке из диполей бора, оборачивающей пикселу.

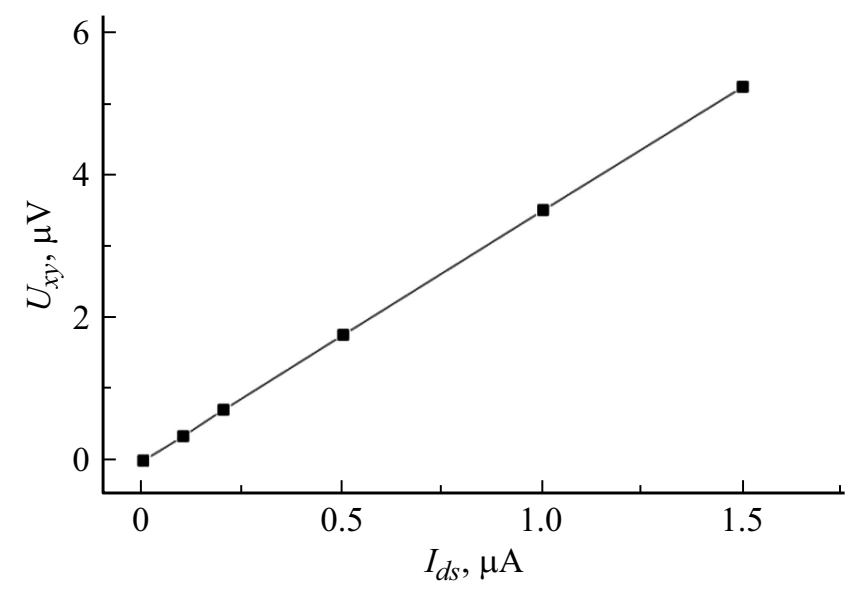

Рис. 6. Зависимость напряжения $U_{x y}$ наносандвича на основе $\mathrm{SiC}$ от величины продольного тока $I_{d s} ; T=300 \mathrm{~K}$.

создает магнитное поле $B$. Это поле можно оценить, приняв во внимание возможность для $I_{d s}$ образовывать контуры. В модели витка с током

$$
B \approx \mu_{0} \frac{I_{d s}}{2 r}
$$

где эффективный радиус $r$ связывается соотношением $r=\sqrt{S / \pi}$ с площадью $S$, которую охватывает контур.

Таким образом, пропускание продольного тока вызывает появление потока $\Phi=B S$ на площади $S$ и изменение потока $\Delta \Phi$ в находящейся внутри этой площади индивидуальной пикселе удвоенной длины; в ней этот процесс приводит также к возникновению генерационного тока:

$$
I_{\text {gen }}=\frac{U_{x y}}{R_{\text {pixel }}}
$$

где $R_{\text {pixel }}=h /\left(4 e^{2}\right)$ для случая пикселы удвоенной длины, а величина $U_{x y}$ есть напряжение, измеренное на $x y$-контактах структуры в зависимости от $I_{d s}$. Результаты таких измерений приведены на рис. 6 , откуда следует $U_{x y}=3.5 \mathrm{OM} \cdot I_{d s}$.
Частота испускаемого излучения может быть найдена в соответствии с формулой Фарадея:

$$
I_{\mathrm{gen}}=\frac{\Delta E}{\Delta \Phi}=\frac{h v}{\Delta \Phi} .
$$

Изменение потока в индивидуальной пикселе удвоенной длины

$$
\Delta \Phi=\frac{m}{N} \Phi_{0}
$$

зависит от их числа $N=S /\left(2 S_{\text {pixel }}\right)$ внутри площади $S$ и от числа $m$ квантов потока $\Phi_{0}=\frac{h}{2 e}$, которые захватываются на $N$ пиксел; $m$ принимает значения $1,2, \ldots, \frac{B S}{h /(2 e)}$, последнее из которых отвечает равномерному заполнению. Частота при этом равна

$$
v=I_{\text {gen }} \frac{m}{N} \frac{1}{2 e} \text {. }
$$

В случае $I_{d s}=30 \mathrm{мA}$ получается $I_{\mathrm{gen}}=16.27$ мкА. Если контур $I_{d s}$ охватывает площадь краевого канала $S_{d s}=4200$ мкм $\times 1.54 \mathrm{Hм}=6.5 \cdot 10^{-12} \mathrm{M}^{2}$, то $\frac{m}{N}=\frac{41}{15}$ при равномерном заполнении. При этом значение частоты при минимальном изменении потока: $v\left(\frac{m}{N}=\frac{1}{15}\right)$ $=3.389$ ТГц. Если контур $I_{d s}$ охватывает площадь всего образца $S_{\text {device }}=4200$ мкм $\times 200$ мкм $=8.4 \cdot 10^{-7} \mathrm{M}^{2}$, то в этих условиях $\frac{m}{N} \approx \frac{3}{412}$ при равномерном заполнении. Значение частоты при минимальном изменении потока: $v\left(\frac{m}{N}=\frac{1}{412}\right)=0.123$ ТГц. Полученные значения хорошо согласуются с величинами 3.4 и 0.12 ТГц, которые обнаруживаются при детальном изучении особенностей полученных спектров (см. далее).

Так, в среднем (до 27 мкм) и дальнем (до 333 мкм) ИК-диапазонах длин волн на спектрах присутствуют модуляции. В модели резонаторов Фабри-Перо расстояние $\Delta v$ между соседними пиками связывается с геометрической длиной $L_{0}$ резонатора [27]:

$$
\Delta v=\frac{c}{2 L_{0} n}
$$

где $c$ - скорость света в вакууме, $n-$ показатель преломления среды. Обнаруженные особенности соответствуют величинам модуляционных частот $\Delta v=0.12$ ТГц (рис. 7) и $\Delta v=3.4$ ТГц (рис. 8). При значении $n=2.55$ для карбида кремния (база данных NSM [28]) величине $\Delta v=0.12$ ТГц соответствует резонатор длины $L_{0}=490.0$ мкм, а величине $\Delta v=3.4$ ТГц соответствует резонатор длины $L_{0}=17.3$ мкм.

Дефекты, разделенные таким характерным микронным расстоянием, возникают спонтанно на дислокациях и других дефектах кремниевой подложки в условиях протекания реакции (1) при низких значениях давления CO [18]. При этом на поверхности получающейся пленки $\mathrm{SiC}$ образуются открытые, выходящие на поверхность подложки ямки травления, напоминающие „жерла вулканов“, сквозь которые удаляется (из глубины подложки) газ $\mathrm{SiO}$. Такой случай изображен на рис. 9, где приведено 
изображение поверхности $\mathrm{SiC}$ на $\mathrm{Si}$, снятой с использованием профилометра New View-6000 фирмы Zygo; светлым цветом отмечены бо́льшие значения по координате $z$, темным цветом - меньшие. С увеличением давления СО до необходимого значения и добавления в систему $\mathrm{SiH}_{4}$ скорости образования зародышей $\mathrm{SiC}$ на гладких участках поверхности и на дислокациях становятся сравнимы. В результате поверхность пленки становится гладкой. Однако подобные микродефекты могут возникать на краях холловской структуры (рис. 1) в процессе легирования в условиях неравновесной диффузии из газовой фазы в избыточном потоке кремниевых вакансий с поверхности. В результате в краевом канале формируется система встроенных микрорезонаторов, отвечающих частоте $\Delta v=3.4$ ТГц.

Резонаторы с миллиметровым характерным размером присутствуют в структуре после формирования

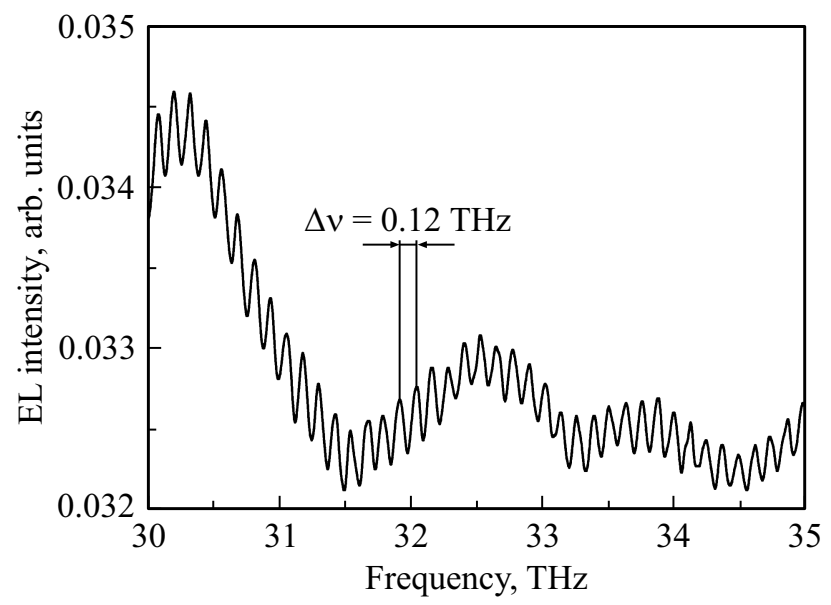

Pис. 7. Осцилляции Фабри-Перо в спектре электролюминесценции исследуемого образца, отвечающие модуляционной частоте 0.12 ТГц; $I_{d s}=30 \mathrm{MA}, T=300 \mathrm{~K}$.

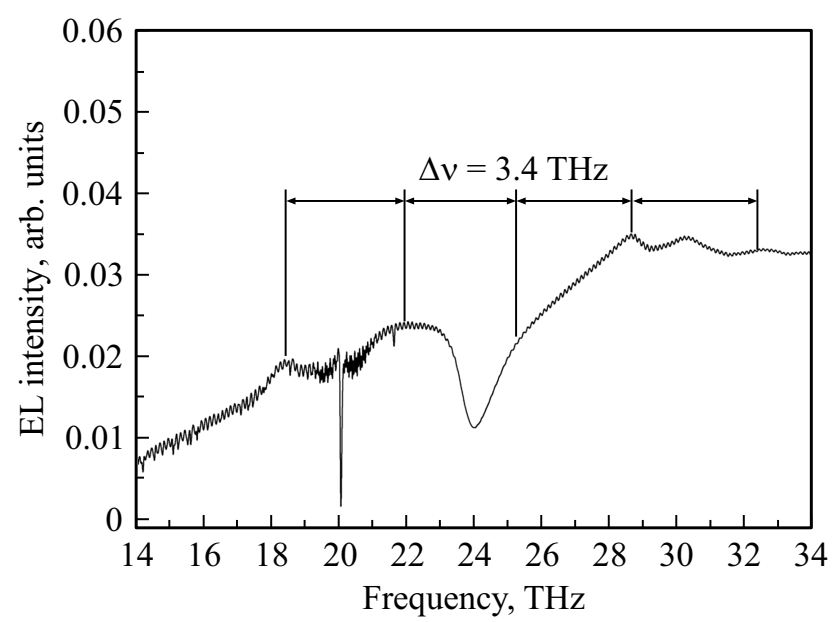

Рис. 8. Осцилляции Фабри-Перо в спектре электролюминесценции исследуемого образца, отвечающие модуляционной частоте 3.4 ТГц; $I_{d s}=30 \mathrm{MA}, T=300 \mathrm{~K}$. Провал на частоте 20 ТГц связан с линиями поглощения $\mathrm{CO}_{2}$.

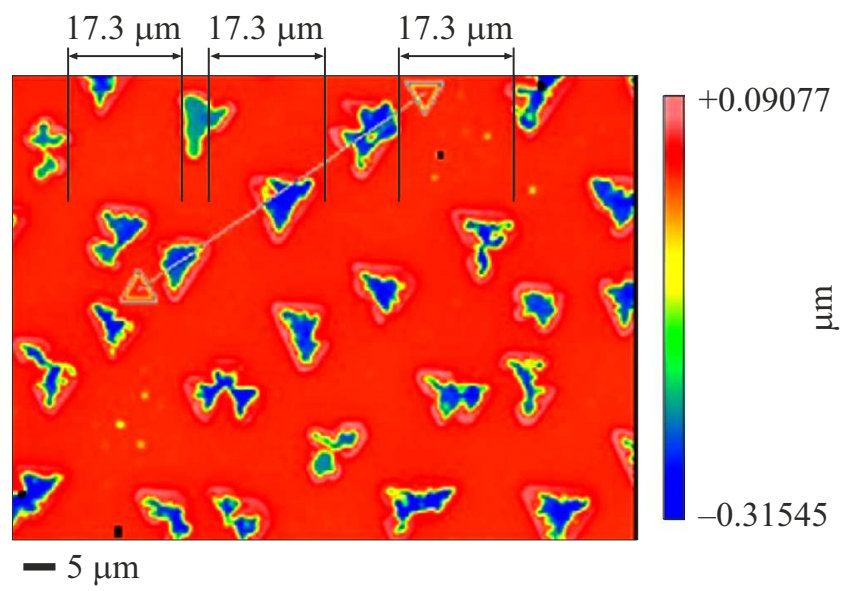

Рис. 9. Изображение поверхности $\mathrm{SiC}$ на $\mathrm{Si}$ в условиях роста пленки при низком давлении СО и отсутствии $\mathrm{SiH}_{4}$. Микродефекты формируют системы микрорезонаторов длины 17.3 мкм, отвечающих частоте 3.4 ТГц. Цветом показано значение координаты $z$ в мкм (по данным работы $[18]$ ). (Цветной вариант рисунка представлен в электронной версии статьи).

контактных площадок: частоте $\Delta v=0.12$ ТГц отвечают области с размером $f / 2 \sim 0.5$ мм между вертикальными контактами (см. рис. 1).

\section{4. Заключение}

Таким образом, была обнаружена и исследована электролюминесценция из наноструктур карбида кремния, полученных методом согласованного замещения атомов. Спектры электролюминесценции регистрировались в среднем и дальнем ИК-диапазонах с помощью фурьеспектрометра Bruker Vertex 70 при комнатной температуре в условиях пропускания продольного тока исток-сток в структурах с холловской геометрией. Обнаружена амплитудная и частотная модуляция полученных спектров в терагерцовом частотном диапазоне, 3.4 и 0.12 ТГц. Обнаруженное терагерцовое излучение возникает вследствие квантового эффекта Фарадея в условиях захвата одиночных квантов магнитного потока в краевых каналах наноструктуры. Одиночные кванты магнитного потока, индуцируемые при протекании тока исток-сток, приводят в рамках предлагаемой модели квантового эффекта Фарадея к генерации тока в краевых каналах и, соответственно, к терагерцовому излучению, частота которого зависит от геометрических параметров исследуемых наноструктур.

\section{Финансирование работы}

Работа выполнена при финансовой поддержке гранта РНФ (грант № 20-12-00193). 


\section{Благодарности}

Синтез слоя $\mathrm{SiC}$ на $\mathrm{Si}$ проводился с использованием оборудования уникальной научной установки „Физика, химия и механика кристаллов и тонких пленок“ ФГУП ИПМаш РАН (Санкт-Петербург).

\section{Конфликт интересов}

Авторы заявляют, что у них нет конфликта интересов.

\section{Список литературы}

[1] M. Danciu, T. Alexa-Stratulat, C. Stefanescu, G. Dodi, B.I. Tamba, C. Teodor Mihai, G.D. Stanciu, A. Luca, I.A. Spiridon, L.B. Ungureanu, V. Ianole, I. Ciortescu, C. Mihai, G. Stefanescu, I. Chirila, R. Ciobanu, V.L. Drug. Materials, 12 (9), 1519 (2019).

[2] S. Zhong. Front. Mech. Eng., 14 (3), 273 (2019).

[3] A.K. Panwar, A. Singh, A. Kumar, H. Kim. IJET-IJENS, 13, 33 (2013).

[4] R. Lewis. J. Phys. D: Appl. Phys., 47 (37), 374001 (2014).

[5] L. Consolino, S. Bartalini, P. De Natale. J. Infr. Milli Terahz Waves, 38, 1289 (2017).

[6] Е.М. Гершензон, М.Б. Голант, А.А. Негирев, В.С. Савельев. Лампы обратной волны миллиметрового и субмиллиметрового диапазонов волн, под ред. Н.Д. Девяткова (М., Радио и связь, 1985).

[7] Q. Sun, Y. He, E.P.J. Parrott, E.P. MacPherson. J. Biophotonics, 11 (2), e201700111 (2018).

[8] https://www.menlosystems.com/products/thz-time-domain-solutions/terak15-terahertz-spectrometer/

[9] R. Köhler, A. Tredicucci, F. Beltram, H.E. Beere, E.H. Linfield, A.G. Davies, D.A. Ritchie, R.C. Iotti, F. Rossi. Nature, 417, 156 (2002).

[10] J. Faist, F. Capasso, D.L. Sivco, A.L. Hutchinson, A.Y. Cho. Science, 264, 553 (1994).

[11] L. Ozyuzer, A.E. Koshelev, C. Kurter, N. Gopalsami, Q. Li, M. Tachiki, K. Kadowaki, T. Yamamoto, H. Minami, H. Yamaguchi, T. Tachiki, K.E. Gray, W.-K. Kwok, U. Welp. Science, 318, 1291 (2007).

[12] N.T. Bagraev, P.A. Golovin, V.S. Khromov, L.E. Klyachkin, A.M. Malyarenko, V.A. Mashkov, B.A. Novikov, A.P. Presnukhina, A.S. Reukov, K.B. Taranets. J Altern. Complement Integr. Med., 6, 112 (2020).

[13] Н.Т. Баграев, Л.Е. Клячкин, А.А. Кудрявцев, А.М. Маляренко, В.В. Романов. ФТП, 43 (11), 1481 (2009).

[14] Н.Т. Баграев, Л.Е. Клячкин, А.М. Маляренко, А.И. Рыскин, А.С. Щеулин. ФТП, 39 (5), 557 (2005).

[15] С.А. Кукушкин, А.В. Осипов. ФТТ, 50, 1188 (2008).

[16] С.А. Кукушкин, А.В. Осипов. ДАН, 444, 266 (2012).

[17] С.А. Кукушкин, А.В. Осипов. Изв. РАН. Механика твердого тела, № 2, 122 (2013).

[18] S.A. Kukushkin, A.V. Osipov. J. Phys. D: Appl. Phys., 47 (31), 313001 (2014).

[19] С.А. Кукушкин, А.В. Осипов, Н.А. Феоктистов. ФТТ, 56, 1457 (2014).

[20] S.A. Kukushkin, A.V. Osipov. J. Phys. D: Appl. Phys., 50 (46), 464006 (2017).
[21] Л.М. Сорокин, Н.В., Веселов, М.П. Щеглов, А.Е. Калмыков, А.А. Ситникова, Н.А. Феоктистов, А.В. Осипов, С.А. Кукушкин. Письма ЖТФ, 34 (22), 88 (2008).

[22] С.А. Кукушкин, А.В. Осипов. Письма ЖТФ, 46 (22), 3 (2020).

[23] Н.Т. Баграев, С.А. Кукушкин, А.В. Осипов, В.В. Романов, Л.Е. Клячкин, А.М. Маляренко, В.С. Хромов. ФТП, 55 (2), 103 (2021).

[24] N.T. Bagraev, V.Yu. Grigoryev, L.E. Klyachkin, A.M. Malyarenko, V.A. Mashkov, V.V. Romanov. Semiconductors, 50 (8), 1025 (2016).

[25] I.E. Gordon, L.S. Rothman, C. Hill, R.V. Kochanov, Y. Tan, P.F. Bernath, M. Birk, V. Boudon, A. Campargue, K.V. Chance, B.J. Drouin, J.M. Flaud et. al. J. Quant. Spectrosc. Radiat. Transfer, 203, 3 (2017).

[26] N.T. Bagraev, L.E. Klyachkin, A.A. Kudryavtsev, A.M. Malyarenko. J. Modern Phys., 3, 1771 (2012).

[27] N. Hodgson, H. Weber. Laser Resonators and Beam Propagation (Fundamentals, Advanced Concepts, Applications, Springer, 2005).

[28] http://www.ioffe.ru/SVA/NSM

Редактор Г.А. Оганесян

\section{Terahertz emission from silicon carbide nanostructures}

N.T. Bagraev ${ }^{1,2}$, S.A. Kukushkin ${ }^{1}$, A.V. Osipov' ${ }^{1}$, L.E. Klyachkin ${ }^{2}$, A.M. Malyarenko ${ }^{2}$, V.S. Khromov ${ }^{1,2}$

${ }^{1}$ Institute for Problems in Mechanical Engineering of the Russian Academy of Sciences,

199178 St. Petersburg, Russia

2 loffe Institute,

194021 St. Petersburg, Russia

Abstract For the first time, electroluminescence was discovered in the middle and far infrared ranges from silicon carbide nanostructures on silicon, obtained in the framework of the Hall geometry. Silicon carbide on silicon was grown by the method of substitution of atoms on silicon. The electroluminescence from the edge channels of nanostructures is induced due to the longitudinal drain- source current. The electroluminescence spectra obtained in the terahertz frequency range, $3.4 \mathrm{THz}, 0.12 \mathrm{THz}$, arise due to the quantum Faraday effect. Within the framework of the proposed model, the longitudinal current induces a change in the number of magnetic flux quanta in the edge channels, which leads to the appearance of a generation current in the edge channel and, accordingly, to terahertz radiation. 